\title{
Intravenous injection of adult human bone marrow mesenchymal stromal cells attenuates spinal cord ischemia/reperfusion injury in a murine aortic arch crossclamping model
}

Hidekazu Nakai, MD, ${ }^{\mathrm{a}}$ Yasuyuki Fujita, MD, PhD, ${ }^{\mathrm{b}}$ Satoru Masuda, MT, ${ }^{\mathrm{b}}$ Miki Komatsu, MT, ${ }^{\mathrm{b}}$ Ayumi Tani, MT, ${ }^{\mathrm{b}}$ Yutaka Okita, MD, PhD, ${ }^{\mathrm{c}}$ Kenji Okada, $\mathrm{MD}, \mathrm{PhD},{ }^{\mathrm{a}}$ and Atsuhiko Kawamoto, MD, $\mathrm{PhD}^{\mathrm{b}}$

\section{ABSTRACT}

Objective: We sought to investigate the efficacy of human bone marrow mesenchymal stem/stromal cell (hBM-MSC) in a murine spinal cord ischemia/reperfusion (SCIR) model.

Methods: $\mathrm{C} 57 \mathrm{BL} / 6 \mathrm{~J}$ mice were subjected to SCIR by crossclamping the aortic arch and left subclavian artery for 5.5 minutes. Two hours after reperfusion, hBM-MSCs (hBM-MSC group) or phosphate-buffered saline (control group) were intravenously injected without immunosuppressant. Hindlimb motor function was assessed until day 28 after reperfusion using the Basso Mouse Scale (BMS). The lumbar spinal cord was harvested at hour 24 and day 28 , and the histologic number of NeuN-positive motor neurons in 3 cross-sections of each lumbar spinal cord and the gene expression were evaluated.

Results: BMS score was o throughout the study period in all control mice. BMS score was significantly greater in the hBM-MSC group than the control group from hour $8(P<.05)$ to day $28(P<.01)$. The numbers of motor neurons at hour $24(P<.01)$ and day $28(P<.05)$ were significantly preserved in the hBMMSC group than the control group. mRNA expression levels of proinflammatory cytokines were significantly lower $(P<.05)$, and those of insulin-like growth factor-1 $(P<.01)$ and proangiogenic factors $(P<.05)$ were significantly greater in the hBMMSC group than the control group at hour 24 .

Conclusions: hBM-MSC therapy may attenuate SCIR injury by preserving motor neurons, at least in part, through inhibition of proinflammatory cytokines and upregulation of proangiogenic factors in the reperfusion-injured spinal cord. (JTCVS Open 2021;7:23-40)

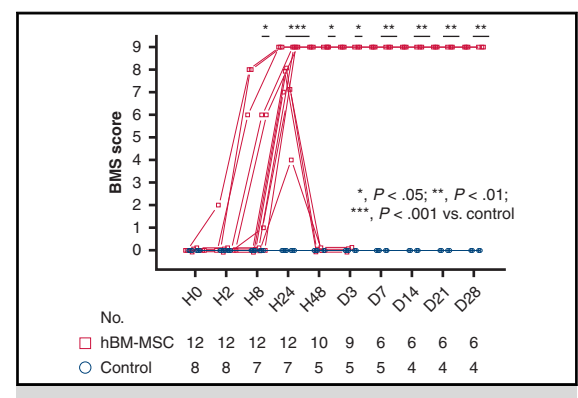

Intravenous injection of hBM-MSC attenuated paraplegia associated with SCIR.

\section{CENTRAL MESSAGE}

hBM-MSC therapy may attenuate SCIR injury by preserving motor neurons through inhibition of proinflammatory cytokines and upregulation of proangiogenic factors in the reperfusion-injured spinal cord.

\section{PERSPECTIVE}

A significant neuroprotection against SCIR injury was achieved by intravenous injection of hBMMSCs in immunocompetent mice. hBM-MSCs have already been commercially available as allogeneic and autologous cell products for GVHD and traumatic spinal cord injury, respectively, in clinical practice. The present results encourage further investigations for clinical application of hBM-MSCs to SCIR injury.

See Commentaries on pages 41,43 , and 45 .

\footnotetext{
From the ${ }^{\mathrm{a}}$ Division of Cardiovascular Surgery, Department of Surgery, Kobe University Graduate School of Medicine, Kobe; ${ }^{\mathrm{b}}$ Translational Research Center for Medical Innovation, Foundation for Biomedical Research and Innovation at Kobe, Kobe; and ${ }^{\mathrm{c} C}$ ardiovascular Center, Takatsuki General Hospital, Takatsuki, Japan. This work was supported by a Grants-in-Aid for Scientific Research (C) Grant Number JP25460477 to Dr Okita from Japan Society for the Promotion of Science and by grants from SENSHIN Medical Research Foundation to Dr. Kawamoto.

Received for publication Oct 20, 2020; accepted for publication June 4, 2021; available ahead of print July 1, 2021
}

\footnotetext{
Address for reprints: Atsuhiko Kawamoto, MD, PhD, Translational Research Center for Medical Innovation, Foundation for Biomedical Research and Innovation at Kobe, 2-2 Minatojima-Minamimachi, Chuo-ku, Kobe, Hyogo 650-0047, Japan (E-mail: kawamoto@fbri.org).

2666-2736

Copyright (c) 2021 The Author(s). Published by Elsevier Inc. on behalf of The American Association for Thoracic Surgery. This is an open access article under the CC BY-NC-ND license (http://creativecommons.org/licenses/by-nc-nd/4.0/). https://doi.org/10.1016/j.xjon.2021.06.008
} 


$\begin{array}{ll}\text { Abbreviations and Acronyms } \\ \text { BM } & =\text { bone marrow } \\ \text { BMS } & =\text { Basso Mouse Scale } \\ \text { EV } & =\text { extracellular vesicle } \\ \text { hBM-MSC } & =\text { human bone marrow mesenchymal } \\ & \text { stem/stromal cell } \\ \text { IGF-1 } & =\text { insulin-like growth factor-1 } \\ \text { IL-10 } & =\text { interleukin-10 } \\ \text { LSA } & =\text { left subclavian artery } \\ \text { mRNA } & =\text { messenger RNA } \\ \text { PBS } & =\text { phosphate-buffered saline } \\ \text { SCI } & =\text { spinal cord ischemia } \\ \text { SCIR } & =\text { spinal cord ischemia/reperfusion } \\ & \end{array}$

$\square$ Video clip is available online.

Paraplegia or paraparesis induced by spinal cord ischemia (SCI) remains a devastating complication following otherwise-successful thoracic and thoracoabdominal aortic open surgical repair or endovascular repair. During the last 3 decades, various surgical strategies and adjunctive measures to prevent spinal complications have been developed, including reconstruction of the intercostal artery, intraoperative systemic deep hypothermia, cerebrospinal fluid drainage, intraoperative monitoring of motorevoked potentials, perioperative optimizing arterial perfusion pressure, and the use of neurochemical protection or their combination. ${ }^{1}$ Although effective application of these techniques has accomplished certain results, the incidence of postoperative spinal cord complications after surgical repair and endovascular repair remains $13.4 \%$ and $5.2 \%$, respectively, in a meta-analysis. ${ }^{2}$ Therefore, the development of alternative therapeutic strategies for postoperative paraplegia or paraparesis is urgently needed.

The incidence of SCI and subsequent neurologic complications has been clinically and experimentally known to be mainly correlated with the 3 factors: duration and severity of ischemia, failure to establish a spinal cord blood supply, and reperfusion injury. ${ }^{1,3}$ Experimental models of spinal cord ischemia/reperfusion (SCIR) have been developed mainly in pigs, ${ }^{4}$ baboons, ${ }^{5}$ rabbits, ${ }^{6,7}$ and rats. ${ }^{7}$ However, there are limitations of these large animal models, including low reproducibility, high cost, and genetic variation. LangLazdunski and colleagues ${ }^{8}$ and Stone and colleagues ${ }^{9}$ developed a murine SCIR model with high reproducibility for producing immediate paraplegia. Kakinohana and colleagues ${ }^{10}$ and Smith and colleagues ${ }^{11}$ modified the murine model to enable produce delayed paraplegia by shorter ischemic time, 3 to 5 minutes and immediate paraplegia by longer ischemic time, 6 to 9 minutes under a certain core temperature. ${ }^{11}$ Furthermore, they demonstrated that inflammatory chemokines release ${ }^{12}$ and microglia activation $^{10,12}$ in the spinal cord tissue and caspase-3 activation in neurons ${ }^{10}$ correlated with motor neuron degeneration in delayed paraplegia. In contrast, immediate paraplegia may be correlated with microglial activation and innate immunity in the spinal cord lesion. ${ }^{13}$

Mesenchymal stem/stromal cells (MSCs) were first identified and isolated from bone marrow (BM) in $1970^{14}$ and have since been the most preclinically and clinically investigated worldwide among the various kind of somatic stem cells. The unique properties of MSCs include their ease of isolation from multiple tissues, ex vivo expansion capacity, multilineage differentiation potentials, immunomodulatory functions in both innate and adaptive immune systems, and promotion and repair effects on damaged resident cells. ${ }^{15}$ Of note, MSCs suppress the proliferation and function of immune cells such as activated $\mathrm{T}$ cells, B cells, natural killer cells, and dendritic cells in a major histocompatibility complex-unrestricted manner. Therefore, MSCs can be used as an allogeneic cell source. ${ }^{16}$ Recently, it has been suggested that extracellular vesicles (EVs) derived from MSCs can serve as drugs to treat multiple diseases. EVs, usually termed as exosomes or microvesicles, contain a variety of molecules, including proteins, microRNAs, and messenger RNAs (mRNAs) and MSC-derived EVs (MSC$\mathrm{EVs}$ ) show therapeutic effects similar to those that can be achieved by the originating MSCs themselves. ${ }^{17}$ Furthermore, Luk and colleagues ${ }^{18}$ demonstrated that intravenous infusion of live or dead human MSCs evokes a similar molecular genetic response in murine host lungs. Taking into consideration of immune-evasion of MSCs and MSC-EVs containing several therapeutically effective molecules, xenotransplantation of MSCs may be equally possible and effective as auto- or allo-transplantation. The immunomodulatory and multipotent properties greatly encouraged the use of MSCs for the treatment of several diseases including graft versus host disease, Crohn's disease, ischemic heart disease, cartilage defect of knee, and spinal cord injury. ${ }^{19}$ Regarding clinical application of MSCs for spinal cord disease, autologous BM-MSCs for traumatic spinal cord injuries reached governmental/pharmaceutical approval for sale in Japan in 2018. However, until now, any clinical trial of MSCs for SCIR injury has not been reported. Moreover, there are only a few preclinical reports of therapeutic efficacy of allogeneic MSCs for rat SCIR models but not mouse model. ${ }^{20}$

In the present study, we investigated the therapeutic effects of intravenous injection of human BM-MNCs (hBM-MSCs) in an immune competent mouse SCIR model and the underlying histologic and molecular mechanisms. 


\section{METHODS}

\section{Animal Preparation}

Female mice (C57BL/6J; CLEA Japan, Inc.) aged 10 to 21 weeks (body weight, 19.0-25.5 g) were used in this study. Animals were housed 2 to 4 per cage under controlled with a 12-hour light/12-hour dark cycle with lights on at 6:00 $\mathrm{AM}$, temperature controlled at $23.5 \pm 1.5^{\circ} \mathrm{C}$, and humidity at $55 \pm 5 \%$. Food and water were ad libitum before and after surgery. This study was approved by the Institutional Animal Care and Use Committee (Permission number: P130603-R3, approved on June 16th, 2015) on June and carried out according to the Kobe University Animal Experimentation Regulations. All surgery was performed under isoflurane anesthesia, all animals were humanely killed by isoflurane overdose, and all efforts were made to minimize the number of animals used and their suffering throughout the experimental procedures.

\section{Experimental Design}

SCIR was induced in mice at hour 0 . Mice with paraplegia were randomly assigned to either hBM-MSC group or control group. The hBM-MSC group received intravenous injection of hBM-MSCs, and the control group received intravenous injection of phosphate-buffered saline (PBS). No immunosuppressant was administrated after injection. Observation and neurologic assessment were performed at each point until day 28 . Finally, all mice were humanely killed and histologic analysis was performed. Separately, mice were euthanized at hour 8 and at hour 24 after reperfusion to assess localization of transplanted cells and short-term histologic and mRNA expressions, respectively (Figure 1).

\section{Spinal Cord Ischemia/Reperfusion}

SCIR was surgically induced in a mouse model for which the methods of Kakinohana and colleagues ${ }^{10}$ and Smith and colleagues ${ }^{11,12}$ were modified. After the mice were weighed, anesthesia was induced by $5.0 \%$ isoflurane, and trachea was intubated by a $20-\mathrm{G}$ custom-made catheter for mechanical ventilation. Mice were kept in the supine position and anesthesia was maintained by $1.5 \%$ to $2.0 \%$ isoflurane with $100 \%$ oxygen.
The rectal temperature of mice was maintained at $36.5^{\circ} \mathrm{C}$ using a continuous temperature probe (IT-23; Bio Research Center Co Ltd, Nagoya, Japan) with an automatically temperature-controlled operating bed (BWT-100A; Bio Research Center Co Ltd). Subsequently, a laser probe (KU210-068; Unique Medical Co Ltd, Tokyo, Japan) was placed on the skin just above the left femoral artery after shaving skin hair to monitor distal arterial pressure. An intraperitoneal dose of $400 \mathrm{IU} / \mathrm{kg}$ of heparin was administered to all animals immediately prior to surgery.

Following median sternotomy, the aortic arch, left carotid artery, and left subclavian artery (LSA) were exposed. Mice were subjected to SCI by crossclamping of the aortic arch between the left carotid artery and the LSA followed by clamping the origin of the LSA for 4 to 6 minutes. Distal aortic blood flow was continuously monitored at the left femoral artery during SCI and until 10 minutes after SCI using laser Doppler flowmetry (TBF-LC1; Unique Medical Co Ltd). Interruption of distal aortic blood flow was confirmed when a greater than $90 \%$ decrease in distal aortic blood flow was achieved (Figure 2, Video 1).

\section{Preparation of hBM-MSCs}

hBM-MSCs derived from one healthy donor (a 65-year-old white male donor, lot number 4031804.4 and 4031804.5) were obtained from PromoCell GmbH (Heidelberg, Germany). Cells were cultured in Mesenchymal Stem Cell Growth Medium containing Basal Medium and SupplementMix (from PromoCell). Cells were passaged when they were approximately $90 \%$ confluent and were used at passage 4-5.

\section{CM-DiI for Labeling hBM-MSCs}

hBM-MSCs were detached using Detachkit (PromCell) and resuspended at a concentration of $1 \times 10^{6}$ cells $/ \mathrm{mL}$ in PBS. CM-DiI $\left(1,1^{\prime}\right.$-Dioctadecyl-3,3,3',3'-tetramethylindocarbocyanine perchlorate) dye stock was prepared as recommended by the manufacturer (Thermo Fisher Scientific Inc, Waltham, Mass). A confluent layer of $1 \times 10^{6} \mathrm{hBM}-\mathrm{MSCs} / \mathrm{mL}$ was stained using CM-DiI solution $(5 \mu \mathrm{L})$ and was incubated at $37^{\circ} \mathrm{C}$ for $5 \mathrm{mi}-$ nutes, then at $4^{\circ} \mathrm{C}$ for 15 minutes. Next, the cell suspension was

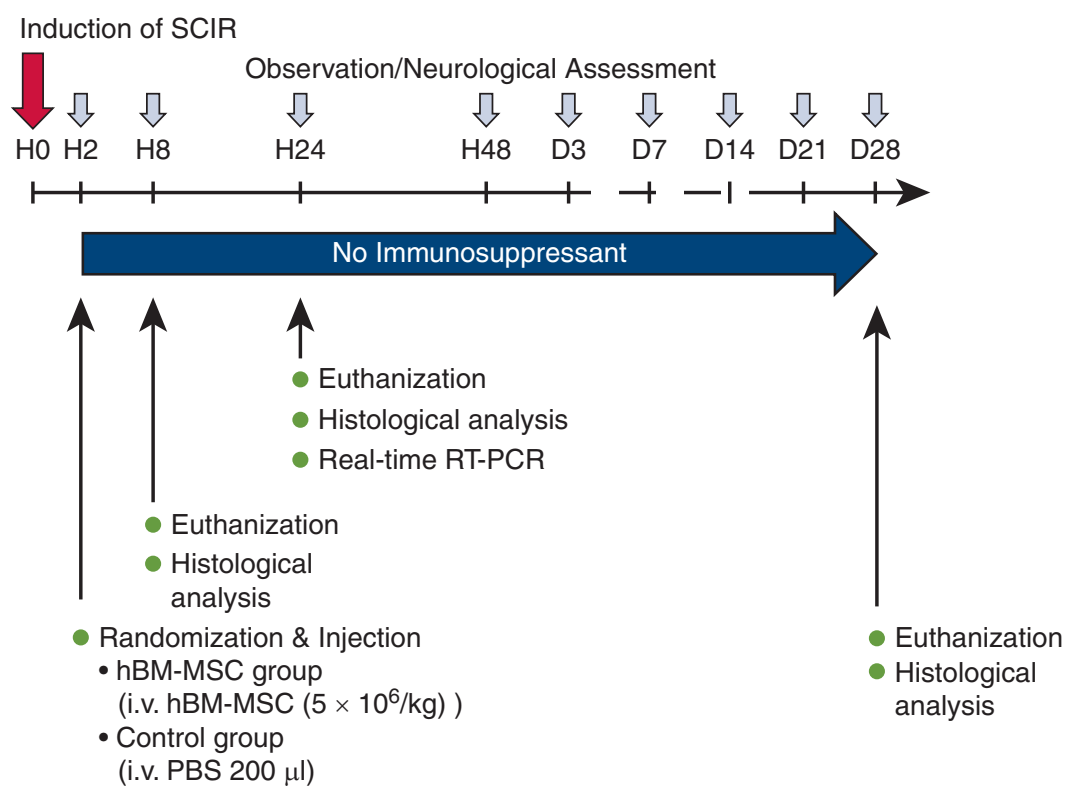

FIGURE 1. Study design. An SCIR injury model was created by aortic arch crossclamping. No immunosuppressants were used, and hBM-MSC or PBS was administered 2 hours after induction. Lower-limb movements were evaluated at each time based on the Basso Mouse Scale. Histologic analysis was performed 8 hours, 24 hours, and 28 weeks later, and real-time RT-PCR was performed 24 hours later. SCIR, Spinal cord ischemia/reperfusion; $h B M-M S C$, human bone marrow derived mesenchymal stem/stromal cell; $P B S$, phosphate-buffered saline; $R T$ - $P C R$, reverse transcription polymerase chain reaction. 


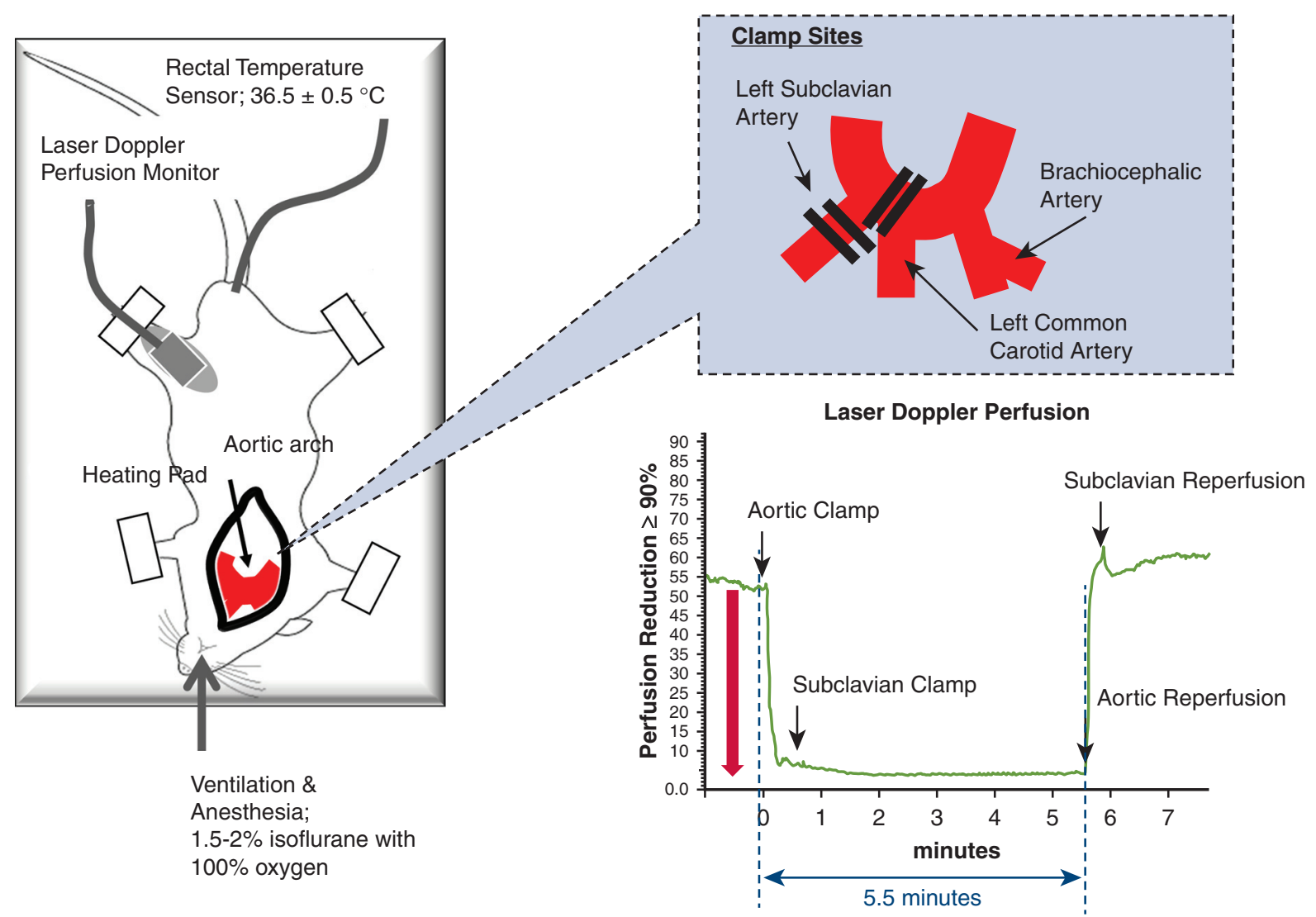

FIGURE 2. Schematic representation of surgical procedures to induce SCIR injury. Mice were intubated and administered with $1.5 \%$ to $2.0 \%$ isoflurane and $100 \%$ oxygen. The rectal temperature of mice was maintained at $36.5^{\circ} \mathrm{C}$ using a continuous temperature probe (IT-23; Bio Research Center Co Ltd, Nagoya, Japan) with an automatically temperature-controlled operating bed (BWT-100A; Bio Research Center Co Ltd). The left femoral artery blood flow was monitored with Laser Doppler Perfusion (KU210-068; Unique Medical Co Ltd, Tokyo, Japan). An intraperitoneal dose of 400 IU/kg of heparin was administered to all animals immediately prior to surgery. Following median sternotomy, the aortic arch, LCA, and LSA were exposed. Mice were subjected to spinal cord ischemia by crossclamping the aortic arch between the LCA and the LSA followed by clamping the origin of the LSA for 5.5 minutes. The upper right figure shows the clamping of the aortic arch and the left subclavian artery. The lower right figure shows laser Doppler perfusion. During aortic arch clamping for 5.5 minutes, lower-extremities blood flow was reduced by $90 \%$.

centrifuged, the media were removed, and the cells were washed twice in PBS ( $\mathrm{pH}$ 7.4). Subsequently, the labeled cells were resuspended in $200 \mu \mathrm{L}$ of PBS and intravenously injected to 2 SCIR mice to detect localization of transplanted hBM-MSCs.

\section{Intravenous Injection}

At hour 2 after reperfusion, mice with paraplegia were randomly assigned to receive either $5 \times 10^{6} / \mathrm{kg} \mathrm{hBM-MSCs}$ suspended in $200 \mu \mathrm{L}$ of PBS (hBM-MSCs) or $200 \mu \mathrm{L}$ of PBS alone (control group). Intravenous injection was performed via tail vein using a $35 \mathrm{G}$ needle. CM-DiI-labelled hBM-MSCs were administered to 2 mice, hBM-MSCs to 12 mice, and PBS to 8 mice. The cell dose $\left(5 \times 10^{6}\right.$ cells $\left./ \mathrm{kg}\right)$ was determined according to the previous report. ${ }^{21}$ This cell dose approximately corresponds to the maximum clinical dose $\left(3.34 \times 10^{6}\right.$ cells $\left./ \mathrm{kg}\right)$ of autologous hBM-MSCs (Stemirac; Nipro, Osaka, Japan) approved for traumatic spinal cord injury in Japan.

\section{Assessment of Hindlimb Motor Function}

Neurologic function in terms of motor nerve function was assessed with the Basso Mouse Scale (BMS), which ranges from a score of 0 for complete paraplegia to a score of 9 for normal function. ${ }^{22}$ Motor nerve function was assessed at hour $0,2,8,24,48$, and 72 and week 1, 2, 3, and 4 after reperfusion.

\section{Histologic Analysis}

Mice were transcardially perfused with $15 \mathrm{~mL}$ of ice-cold PBS under deep aesthesia with an overdose of isoflurane. Cervical through lumbar vertebral columns were removed en bloc, and the spinal cord was harvested by forcefully injecting ice-cold PBS into the spinal column. Lumbar enlargements of spinal cord were directly embedded in OCT compound (Sakura Finetek, Tokyo, Japan), snap frozen in liquid nitrogen, and stored at $-80^{\circ} \mathrm{C}$ as fresh frozen samples. Other organs including brains, hearts, lungs, livers, kidneys, and spleens were also harvested and stored as fresh frozen samples to detect localization of transplanted hBM-MSCs. Spinal cords were transversely sectioned at $12 \mu \mathrm{m}$ on a cryostat. Sections were permeabilized with $0.3 \%$ TritonX-100, and nonspecific binding sites were blocked with blocking solution (Protein Block Serum-Free; Dako, Carpinteria, Calif). Sections were additionally incubated with mouse IgG blocking reagent (M.O.M; Vector Laboratories, Burlingame, Calif). Spinal cord sections were primarily stained with mouse anti-Neu-N (1:500; Chemicon). A secondary antibody used was Alexa Flour 488 conjugated 


\section{Orientation}

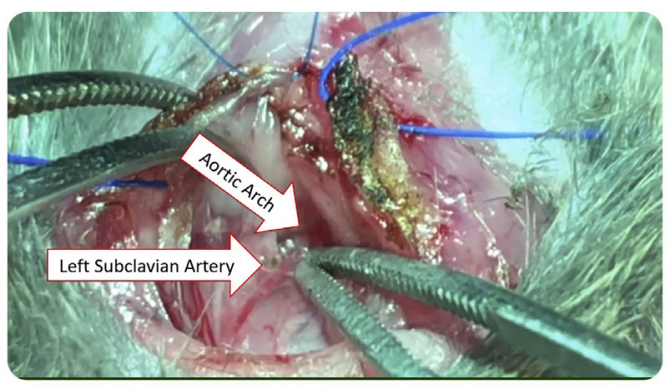

VIDEO 1. Anesthesia was induced by $5.0 \%$ isoflurane, and trachea was intubated by a $20 \mathrm{G}$ custom-made catheter for mechanical ventilation. Mice were kept in the supine position, and anesthesia was maintained by $1.5 \%$ to $2.0 \%$ isoflurane with $100 \%$ oxygen. The rectal temperature of mice was maintained at $36.5^{\circ} \mathrm{C}$ using a continuous temperature probe (IT-23; Bio Research Center Co. Ltd., Nagoya, Japan) with an automatically temperature-controlled operating bed (BWT-100A; Bio Research Center Co Ltd). Thereafter, a laser probe (KU210-068; Unique Medical Co Ltd, Tokyo, Japan) was placed on the skin just above the left femoral artery after shaving skin hair to monitor distal arterial pressure. An intraperitoneal dose of $400 \mathrm{IU} / \mathrm{kg}$ of heparin was administered to all animals immediately before surgery. Following median sternotomy, the aortic arch, left carotid artery (LCA), and left subclavian artery (LSA) were exposed. Mice were subjected to spinal cord ischemia by cross-clamping the aortic arch between the LCA and the LSA followed by clamping the origin of the LSA for 5.5 minutes. Distal aortic blood flow was continuously monitored at the left femoral artery from starting the spinal cord ischemia to 10 minutes after the reperfusion using laser doppler flowmetry (TBF-LC1; Unique Medical Co Ltd). Interruption of distal aortic blood flow was confirmed when a greater than $90 \%$ decrease in distal aortic blood flow was achieved. Finally, we confirmed mice with paralyzed lower-limb movements. The Basso Mouse Scale was judged to be 0 points. Video available at: https://www.jtcvs.org/article/S2666-2736(21)00157-1/fulltext.

goat anti-mouse IgG1 (MP/Invitrogen, Waltham, Mass). Cover slips were placed on slides containing ProLong Gold Antifade Mountant with DAPI liquid mountant (Life Technologies, Carlsbad, Calif). Immunostained sections were observed under a confocal laser scanning microscope (FV1000; Olympus, Tokyo, Japan). For quantitative analysis, motor neurons in the anterior horns were identified according to the following criteria; NeuNpositive, nuclear diameter $>9$ to $10 \mu \mathrm{m}$, and cell body diameter $>20 \mu \mathrm{m} .{ }^{23}$ The numbers of motor neurons in unilateral Rexed laminae VII, VIII, and IX, which corresponds to ventral horn, in 3 cross-sections of each lumbar spinal cord and the cross-sectional areas of the ventral horns at hour 24 and week 4 after reperfusion were measured by using Image $\mathrm{J}$ (National Institutes of Health, Bethesda, Md). The number of NeuNpositive neurons in the ventral horn was counted by the 2 observers blinded for the identification of the groups.

\section{Real-Time Polymerase Chain Reaction Analysis in Lumbar Spinal Cord Tissues}

At hour 24 after reperfusion, spinal cords were rapidly dissected and lumbar enlargements were removed and submerged in RNA stabilization reagent (RNAlater; Ambion, Invitrogen). Total RNA was isolated using
RNeasy Plus Universal Mini Kit (QIAGEN, Tokyo, Japan) according to the manufacturer's protocol. After the first-strand cDNA was synthesized with the use of PrimeScript RT reagent Kit (TaKaRa, Otsu, Japan), realtime quantitative reverse transcription-polymerase chain reaction was performed with ABI Prism 7700 (Applied Biosystems, Foster City, Calif) using SYBR Green Master Mix reagent (Applied Biosystems) according to the manufacturer's protocol. The relative mRNA expression in each gene was normalized to the expression level of glyceralde-hyde-3-phosphate dehydrogenase. Each primer sequence is shown in Table E1.

\section{Statistical Analysis}

Data are expressed as mean \pm standard deviation for continuous variables and median with range for ordinal scales. For 2 different groups, statistical differences were analyzed using the Mann-Whitney $U$ test. BMS score was statistically analyzed using 2-way repeated measures analysis of variance followed by post hoc analysis using Mann-Whitney $U$ test for comparison between 2 groups at each time of observation. Interobserver variation of the number of motor neurons was quantified using linear regression analysis. All statistical analysis was performed using JMP 12 (SAS Institute Inc, Cary, NC).

\section{RESULTS}

\section{Effect of SCI Time on Hindlimb Motor Functional Outcomes}

The relationship between SCI time and hindlimb motor function until hour 48 after reperfusion was explored under the setting of a rectal temperature of $36.5^{\circ} \mathrm{C}$ (Table E2). Types of paraplegia are classified into "immediate paraplegia" and "delayed paraplegia" based on the time of onset of spinal complications after reperfusion. A shorter period (3-5 minutes) of ischemia induces delayed paraplegia, and a longer period (6-9 minutes) induces immediate paraplegia in mice. ${ }^{10,11}$ Four minutes of ischemia produced no observable hindlimb motor function deficit from hour 8 to 48 . Ischemic time of 4.5 minutes induced delayed paraplegia in $50 \%$ of mice and no motor function deficit in $50 \%$ of

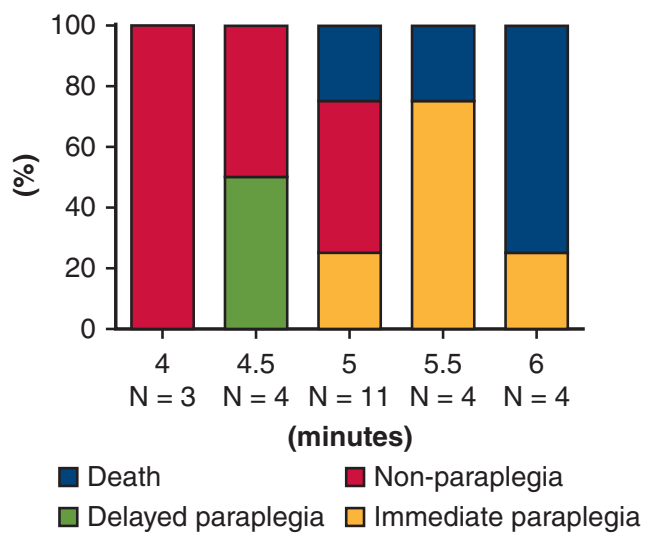

FIGURE 3. Outcomes after SCIR in various ischemic durations. Ischemic time of 4.5 minutes induced delayed paraplegia in $50 \%$ of mice and no motor function deficit in $50 \%$ of mice. Ischemic times of 5, 5.5 and 6 minutes induced immediate paraplegia in $29 \%, 75 \%$, and $25 \%$ of mice, respectively. In particular, 5.5- and 6- minute ischemia induced immediate paraplegia or death, but not delayed paraplegia. Survival rate was higher in 5.5minute than 6-minute ischemia. 


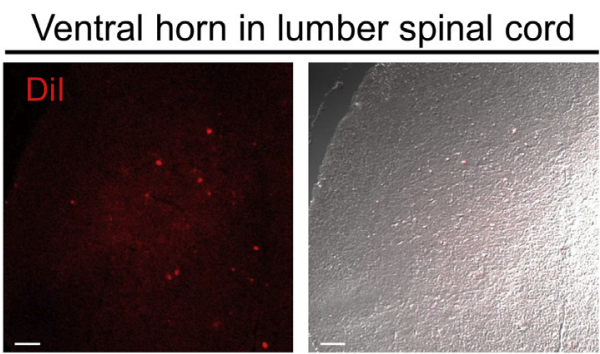

Spleen

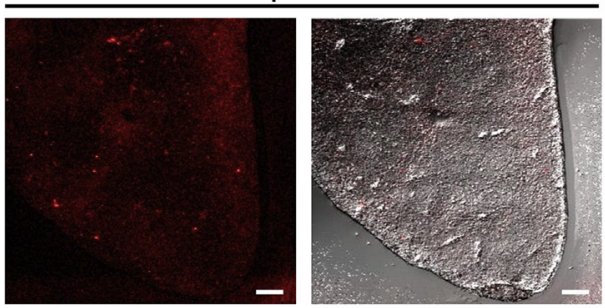

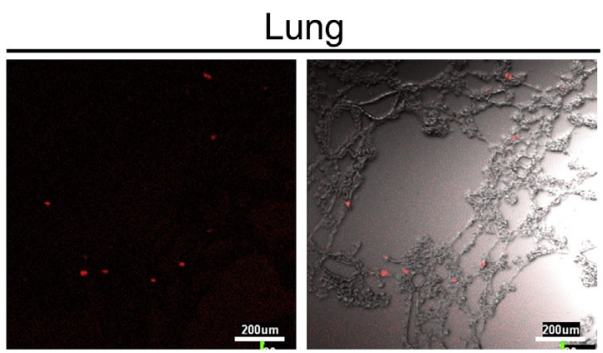

Kidney

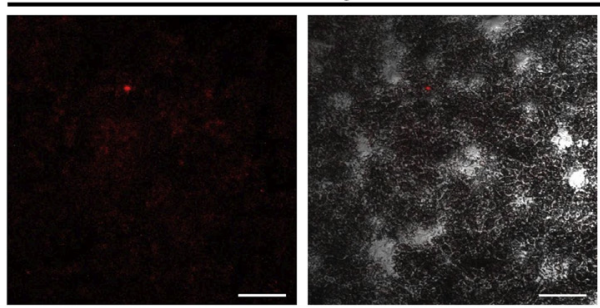

Scale bar $=200 \mu \mathrm{m}$

FIGURE 4. Representative localization of transplanted DiI-labeled hBM-MSCs in vertebral horn in lumbar spinal cord, lung, spleen, and kidney at hour 8 after reperfusion (hour 6 after cell injection). DiI, 1,1'-Dioctadecyl-3,3,3',3'-tetramethylindocarbocyanine perchlorate.

mice. Ischemic times of 5, 5.5, and 6 minutes induced immediate paraplegia in $29 \%, 75 \%$, and $25 \%$ of mice, respectively. In particular, 5.5- and 6- minute ischemia induced immediate paraplegia or death but not delayed paraplegia. Survival rate was greater in 5.5-minute than 6-minute ischemia (Figure 3). Therefore, the 5.5-minute ischemia model (immediate paraplegia model) was selected as the most appropriate method for this study.

\section{Localization of Transplanted hBM-MSCs After Reperfusion}

We histologically examined the localization of DiIlabeled hBM-MSCs in 2 mice. Transplanted cells at hour 8 after reperfusion (6 hours after cell injection) were detected in ventral horn in spinal cord, lung, spleen, and kidney but not in brain, heart, or liver in all mice (Figure 4). These results represent that transplanted hBM-MSCs may home to the ischemia/reperfusion-injured spinal cord in early phase after cell injection.

\section{Motor Functional Outcomes After Reperfusion}

All mice showed paraplegia corresponding to BMS scores of 0 to 2 (median, 0 ; range, 0-2) at hour 2 after reperfusion. Significant intergroup effects were identified with 2-way repeated-measures analysis of variance $(P<.0001$ for group, time and group $\times$ time interaction). BMS score was 0 throughout the study period in all surviving control mice, whereas BMS score started to recover from hour 8 after reperfusion and reached as high as 9 at hour 24 in all mice in hBM-MSC group. The BMS score was significantly greater in the hBM-MSC group surviving mice than the control group surviving mice from at hour
48 to day 28 after reperfusion (Figure 5, $A$ ). Fifty percent mice in each group survived until day 28 . There was no difference in overall survival between the hBM-MSC and control groups during the study period $(P=.8527)$ (Figures 5, B, and E1, and Table E3). In all mice that died in the hBM-MSC group $(\mathrm{N}=6)$, transient recoveries of hindlimb motor function (median of BMS scores, 7.5; range 4-9) were observed at hour 24 after reperfusion; however, these mice fell into complete paraplegia (BMS score 0$)$ again $(\mathrm{N}=4)$ or died $(\mathrm{N}=2)$ at hour 48 , and subsequently, all surviving mice $(\mathrm{N}=4)$ remained complete paraplegia and died until day 7 . In contrast, motor functions continued to maintain normal (BMS score 9) in mice survived until day 28 in the hBM-MSC group $(\mathrm{N}=6)$. These results suggest that intravenous injection of hBM-MSCs may attenuate or improve paraplegia, but not overall survival, after SCIR.

\section{Histopathology of Lumbar Spinal Cords After Reperfusion}

The linear regression analysis showed significant correlation in the number of NeuN-positive motor neurons measured by 2 observers blinded for the identification of the groups (Figure E2). Variations between observers were calculated by dividing (difference between both measurements) by (average of both measurements) in each measurement. As a result, the variation of the counting Neu-N-positive neurons in the ventral horn at 24 hours was $13.2 \pm 13.2 \%$, and the variation at day 28 was $5.8 \pm 11.6 \%$. The number of Neu-N-positive motor neurons of the lumbar enlargement was significantly greater in hBM-MSC group than control group at hour 24 after reperfusion 


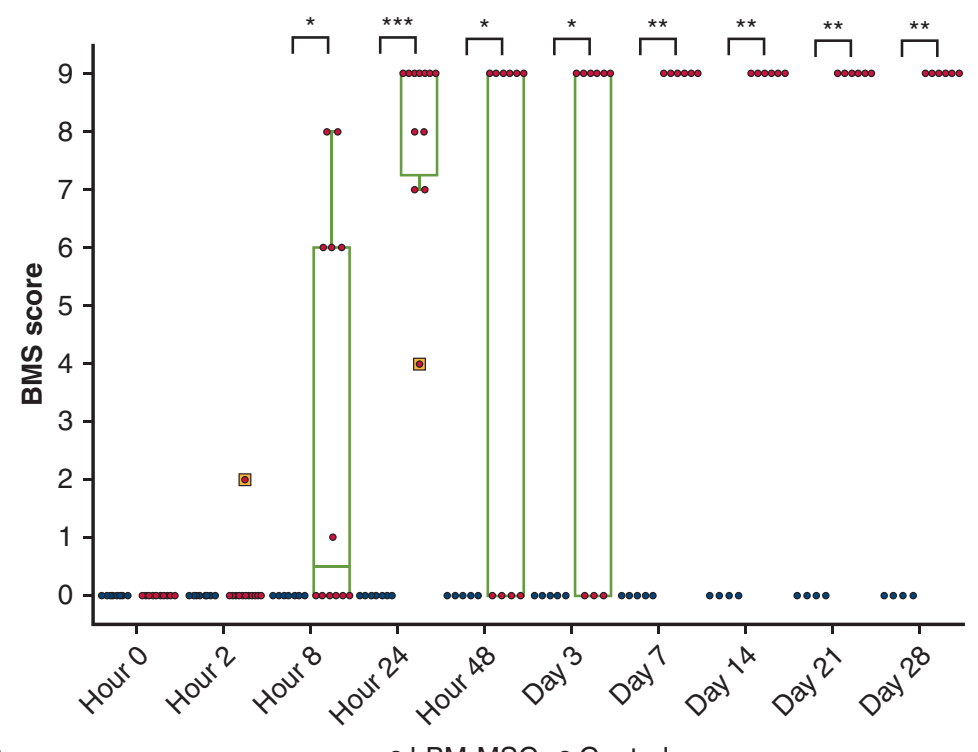

A

- hBM-MSC • Control
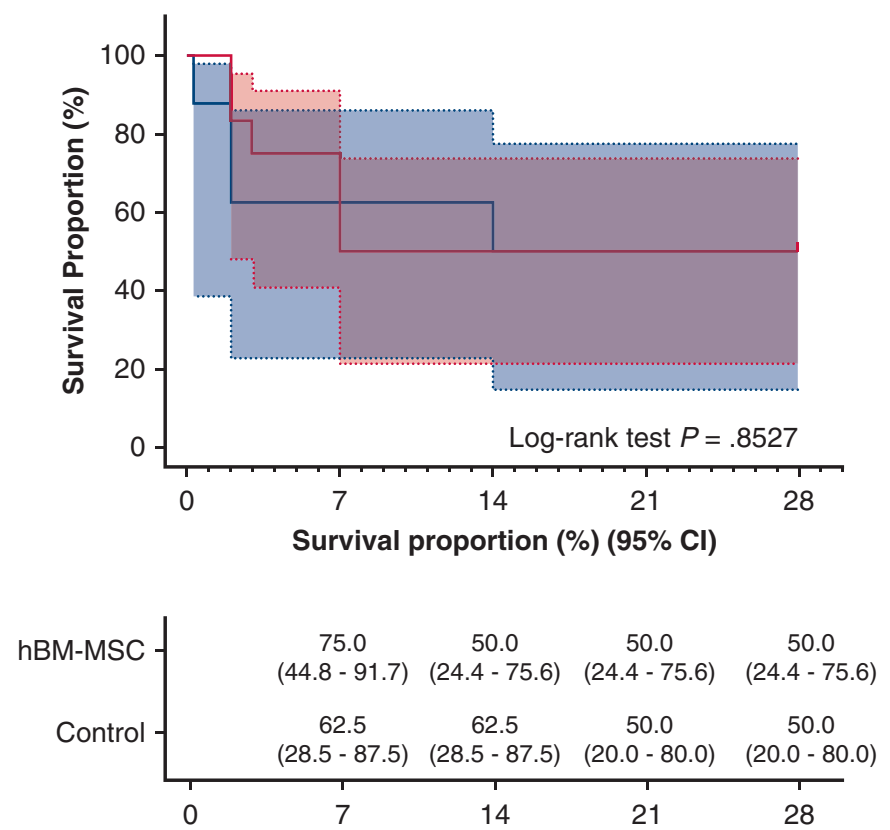

Number at risk

\begin{tabular}{|c|c|c|c|c|c|}
\hline hBM-MSC & 12 & 9 & 6 & 6 & 6 \\
\hline \multirow[t]{3}{*}{ Control } & 8 & 7 & 5 & 4 & 4 \\
\hline & 0 & 7 & 14 & 21 & 28 \\
\hline & \multicolumn{5}{|c|}{ Days after SCIR } \\
\hline
\end{tabular}

B

$\perp \mathrm{hBM}-\mathrm{MSC} \perp$ Control

FIGURE 5. A, BMS score, a motor functional outcome, after reperfusion. Gray line is the median, the top of the box is the 75th percentile, the bottom of the box is the $25^{\text {th }}$ percentile, the whiskers represent the maximum and minimum values excluding the outliers, and the dots surrounded by square represent the outliers. $P$ values were determined by 2 -way repeated measures analysis of variance followed by post hoc analysis using Mann-Whitney $U$ test for comparison between 2 groups at each time of observation. $* P<.05 ; * * P<.01 ; * * * P<.001$ vs control at each time point after reperfusion. B, Long-term survival rate after reperfusion in hBM-MSC and control groups. BMS, Basso Mouse Scale; $h B M-M S C$, human bone marrow mesenchymal stem/stromal cell; $C I$, confidence interval. 


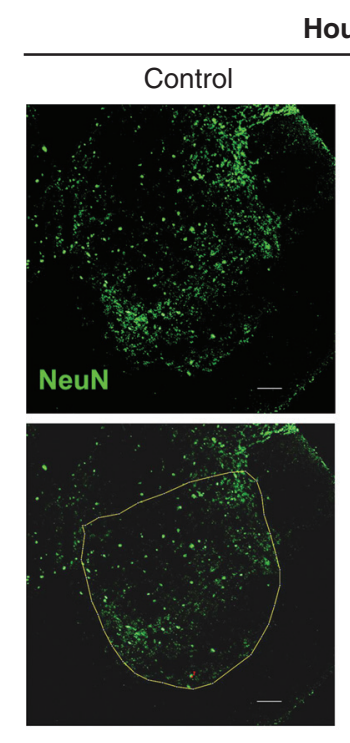

Hour 24
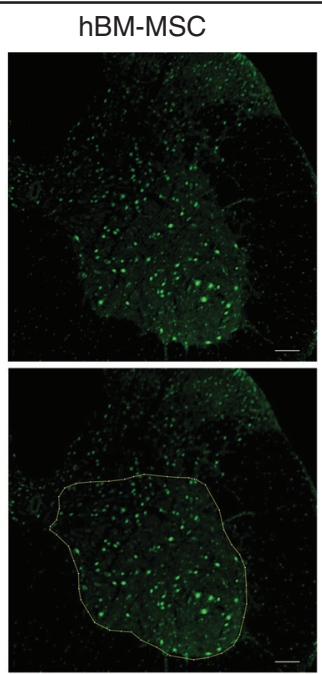

A

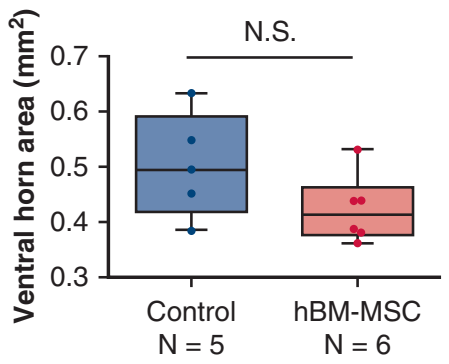

B

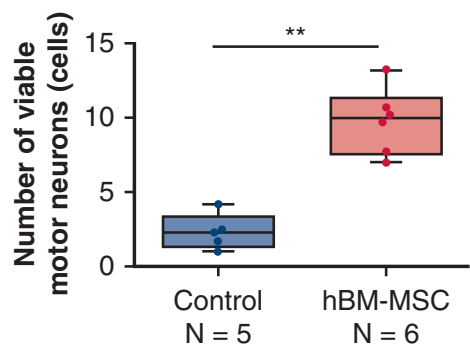

C

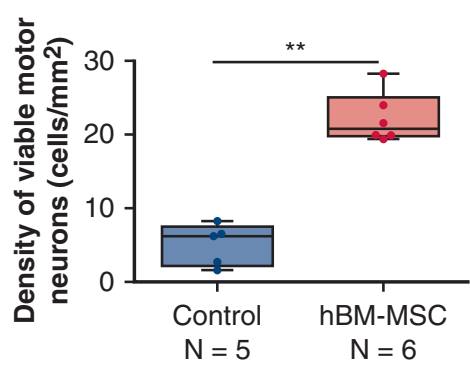

Day 28
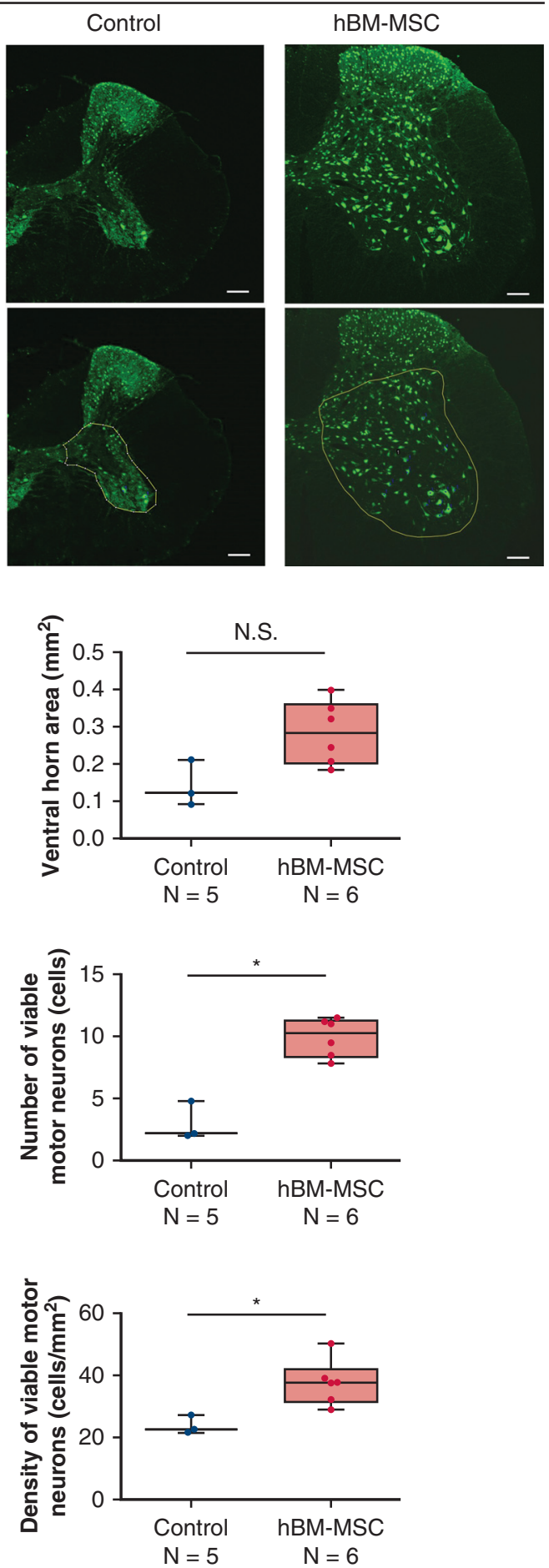

FIGURE 6. A, Representative immunohistochemistry for Neu-N (green) of the lumbar spinal cord sections at hour 24 and day 28 after reperfusion in mice receiving hBM-MSCs. The area surrounded by yellow line indicates the ventral horn. Scale bars $=100 \mu \mathrm{m}$. B, Ventral horn area $\left(\mathrm{mm}^{2}\right)$ of the lumber spinal cord sections at hour 24 and day 28 after reperfusion. C, The number of Neu-N-positive cells indicating viable motor neurons at hour 24 and day 28 after reperfusion. D, Motor neuron density (cells $/ \mathrm{mm}^{2}$ ) in ventral horns. Gray line is the median, the top of the box is the 75th percentile, the bottom of the box is the 25 th percentile, and the whiskers represent the maximum and minimum values. ${ }^{*} P<.05$; $* * P<.01$ vs control. $h B M$-MSC, Human bone marrow mesenchymal stem/stromal cell. 

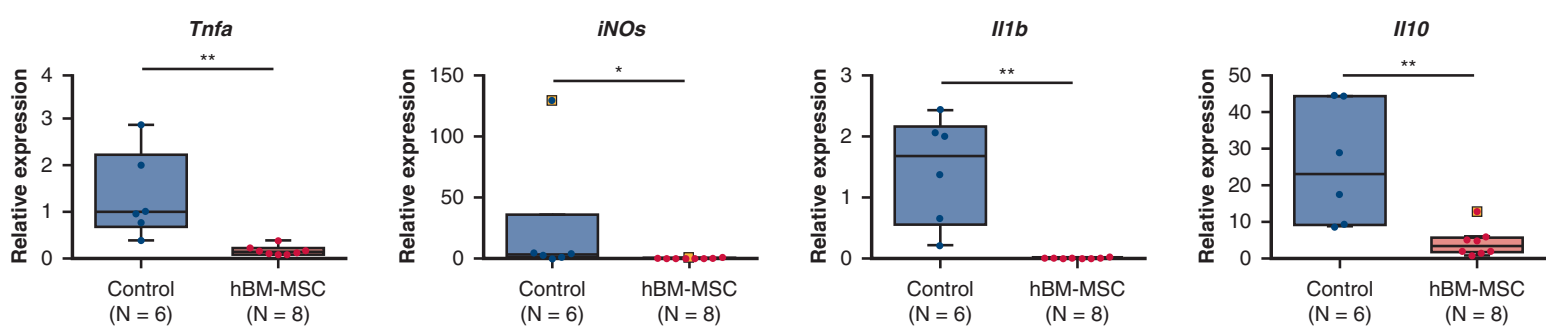

A
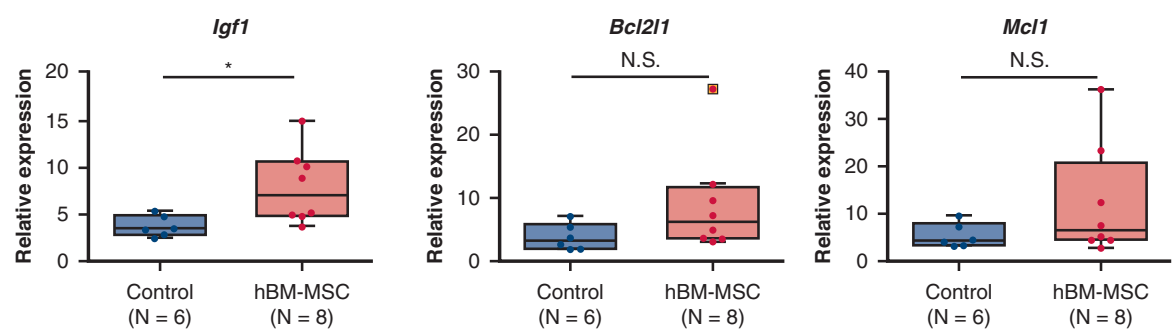

B
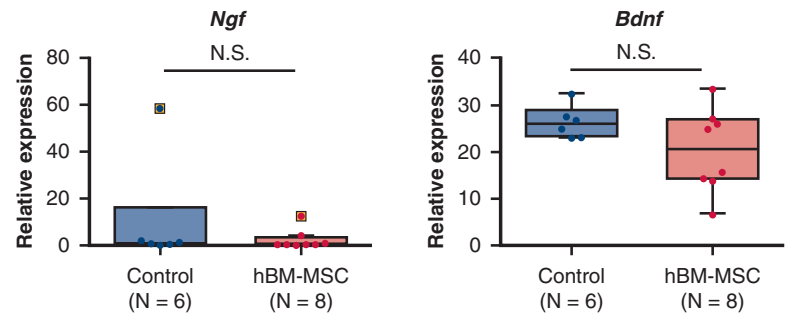

C
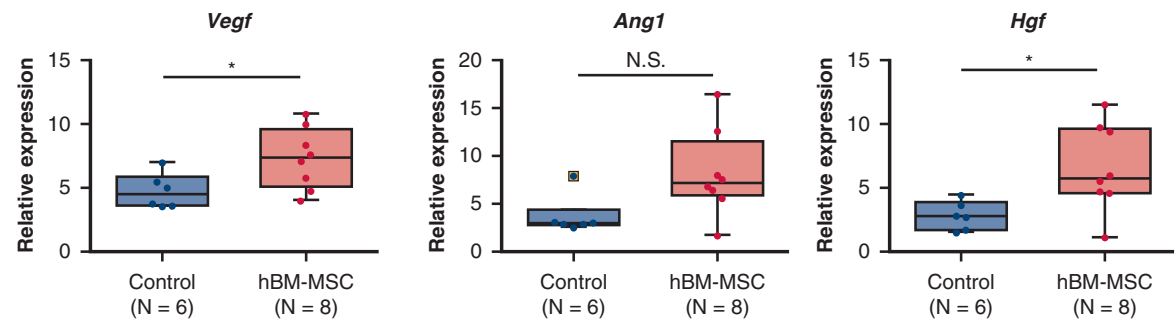

D

FIGURE 7. Real-time RT-PCR analysis for proinflammatory cytokines (A), antiapoptotic factor (B), neurotrophins (C), and angiogenic factors (D) in lumbar spinal cords at hour 24 after reperfusion. Gray line is the median, the top of the box is the 75th percentile, the bottom of the box is the 25 th percentile, the whiskers represent the maximum and minimum values excluding the outliers, and the dots surrounded by square represent the outliers. $* P<.05$; $* * P<.01 \mathrm{vs}$ control. RT-PCR, Reverse transcription polymerase chain reaction; $T N F-\alpha$, tumor necrosis factor- $\alpha ; h B M-M S C$, human bone marrow mesenchymal stem/ stromal cell; iNOs, inducible nitric oxide synthase; Illb, interleukin-1 $\beta$; IL10, interleukin-10; Igfl, insulin-like growth factor- $1 ;$ Bcl2ll, B-cell lymphoma211; N.S., not significant; $M c l 1$, myeloid cell leukemia-1; $N g f$, nerve growth factor; Bdnf, brain-derived neurotrophic factor; Vegf, vascular endothelial growth factor; Ang1, angiopoietin-1; Hgf, hepatocyte growth factor.

$(9.8 \pm 2.2$ vs $2.3 \pm 1.2 ; P<.01)$ and at day $28(9.9 \pm 1.5 \mathrm{vs}$ $3.0 \pm 1.6 ; P<.05$ ) (Figure $6, A$ and $C$ ). There is no significant difference in the cross-sectional areas of the ventral horn of the lumbar spinal cord at hour 24 after reperfusion between the 2 groups. However, the lumbar spinal cords tended to be more atrophic in control group than hBMMNC group at day $28(P=.0933)$ (Figure $6, A$ and $B)$.
The motor neuron density in the ventral horn was significantly greater in hBM-MSC group than control group at hour 24 after reperfusion $(22.2 \pm 3.4$ vs $5.1 \pm 2.8$; $P<.01)$ and at day $28(37.6 \pm 7.3$ vs $23.8 \pm 3.0$; $P<.05$ ) (Figure 6, D). These results indicate that intravenous injection of hBM-MSCs may preserve motor neurons in the lumbar spinal cord following SCIR. 


\section{mRNA Expression of Mouse Cytokines and Growth Factors in Lumbar Spinal Cord at Hour 24 After Reperfusion}

We performed real-time reverse transcription polymerase chain reaction to quantify the mRNA expression of mouse proinflammatory cytokines, anti-inflammatory cytokines, anti-apoptotic factor, neurotrophins, and angiogenic factors in lumbar spinal cords at hour 24 after reperfusion (Table E4). The mRNA expression levels of proinflammatory cytokines including tumor necrosis factor- $\alpha(P<.01)$, inducible nitric oxide synthase $(P<.05)$, and interleukin- $1 \beta(P<.01)$ were significantly lower in hBM-MSC group than control group (Figure 7, A). In contrast, expression level of antiinflammatory cytokine, interleukin-10 (IL-10) was significantly lower in hBM-MSC group than in control group. mRNA expression of insulin-like growth factor-1 (IGF-1), an antiapoptotic factor, was significantly greater in the hBM-MSC group compared with the control group $(P<.01)$. However, there was no significant difference in the mRNA levels of B-cell lymphoma-xL (gene/transcript name BCL2L1) and myeloid cell leukemia-1, which were antiapoptotic proteins, between hBM-MSC group and control group (Figure 7, B). There was no significant difference in the mRNA levels of nerve growth factor and brainderived neurotrophic factor (BDNF) between the 2 groups (Figure 7, C), whereas vascular endothelial growth factor and hepatocyte growth factor were significantly greater $(P<.05 ; P<.05)$ and angiopoietin- 1 tended to be greater $(P=.0814)$ in hBM-MSC group compared with control group (Figure 7,D). These findings suggest that intravenous injection of hBM-MSCs may inhibit proinflammatory cytokines and upregulate angiogenic factors in the reperfusioninjured spinal cord.

\section{DISCUSSION}

The present study demonstrated the effect of intravenous injection of hBM-MSCs on SCIR injury in a model using immunocompetent mice. We selected a murine model among several animal SCIR models because 1 anterior and 2 posterior spinal arteries supply the spinal cord in mice, which is anatomically similar to humans. ${ }^{8}$ Also, ischemia/reperfusion-related genes have been well identified and detailed molecular biological analysis is available in mice.

The main difference between the 2 murine models, the model of Kakinohana and colleagues and Smith and colleagues, to which we referred in the present study, is that they maintained a core temperature of $37.0^{\circ} \mathrm{C}$ during ischemia, using paravertebral muscle (L1-L3) temperature and rectal temperature as indicators, respectively. In the present model, we adopted the rectal temperature, which is technically easier to measure than paravertebral muscle temperature, as an indicator of core temperature and maintained normothermia, $36.5^{\circ} \mathrm{C}$ under anesthesia at room temperature, $23.5 \pm 1.5^{\circ} \mathrm{C}$ during ischemia. As a result, 5.5minute ischemia reproducibly induced immediate paraplegia, which is almost consistent with the results of Smith and colleagues. ${ }^{11}$

SCIR activates cascades leading to neuronal death and neurologic deficits. Although the precise mechanisms of SCIR injury have not yet been fully elucidated, previous studies demonstrated that inflammatory chemokines release, ${ }^{12}$ innate immunity, ${ }^{13}$ and microglia activation ${ }^{10,12}$ in the spinal cord tissue and caspase- 3 activation in neurons ${ }^{10}$ contributed to neuronal degeneration and death. MSCs have been widely investigated as an attractive candidate for cell therapy for broad-ranging clinical applications due to their intriguing multipotencies including immunomodulatory, antiapoptotic, proliferative, angiogenic, and antifibrotic properties as well as multilineage differentiation potentials. ${ }^{24}$ Therefore, some studies have demonstrated the effect of allogenic MSCs administration into rabbit models $^{25-28}$ and rat models ${ }^{20,21,29}$ of SCIR. In addition, human MSCs are thought to be able to avoid allogenic rejection, because they lack human leukocyte antigen class II antigen, and prevent T-cell response and induce an immune-suppressive local microenvironment. ${ }^{30}$ Theoretically, human MSCs were also considered to be available as xenogeneic cells. Actually, some studies demonstrated that there is no difference in the fates of transplanted hBM-MSCs and allogenic BM-MSCs after administration to a cerebral ischemia reperfusion model ${ }^{31}$ and a traumatic spinal injury model ${ }^{32}$ using immunocompetent wild-type mice.

To determine the optimal timing for administration of hBM-MSCs, we first examined the effect of intravenous injection of hBM-MSCs at hour 8 after reperfusion in our preliminary experiment. Injection at hour $8(\mathrm{~N}=3)$ did not result in improvement of hindlimb motor function (data not shown) in the 5.5-minute ischemic model. In a rabbit model, Shi and colleagues ${ }^{26}$ examined the effect of the timing for intrathecal injection of autologous BM-MSCs at hour 2, 24, and 48 after reperfusion (MSC-2h, MSC24h, and MSC-48h). Hindlimb function was better in the MSC-2h group than the other groups throughout the study period (28 days). Therefore, in the present study, we intravenously injected hBM-MSCs at hour 2 after reperfusion. Paraplegia after SCIR remains to be one of the serious complications in thoracic and thoracoabdominal aortic open/endovascular repair even though various countermeasures are taken. In clinical practice, SCIR disorder may occur during the repair procedure, however the occurrence becomes apparent when patients recover from anesthesia a few hours after the onset. Therefore, the timing of intravenous administration of hBM-MSCs in this study (2 hours after reperfusion) would be reasonable considering the clinical situations of the disorder. 


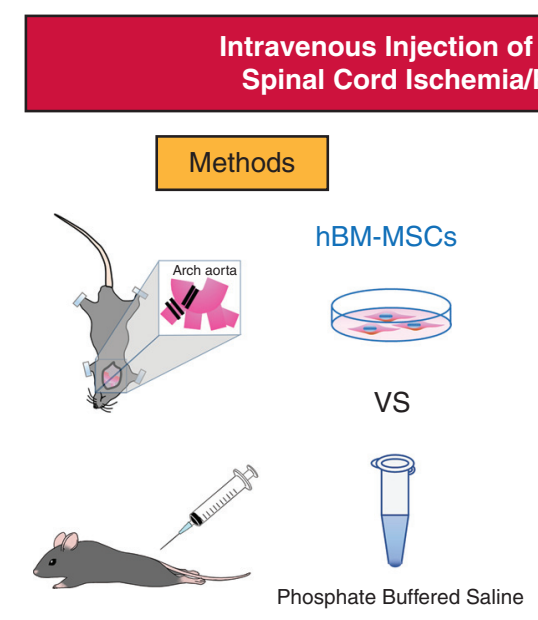

Intravenous Injection of Adult Human Bone Marrow Mesenchymal Stromal Cells Attenuates

Spinal Cord Ischemia/Reperfusion Injury in a Murine Aortic Arch Cross-Clamping Model
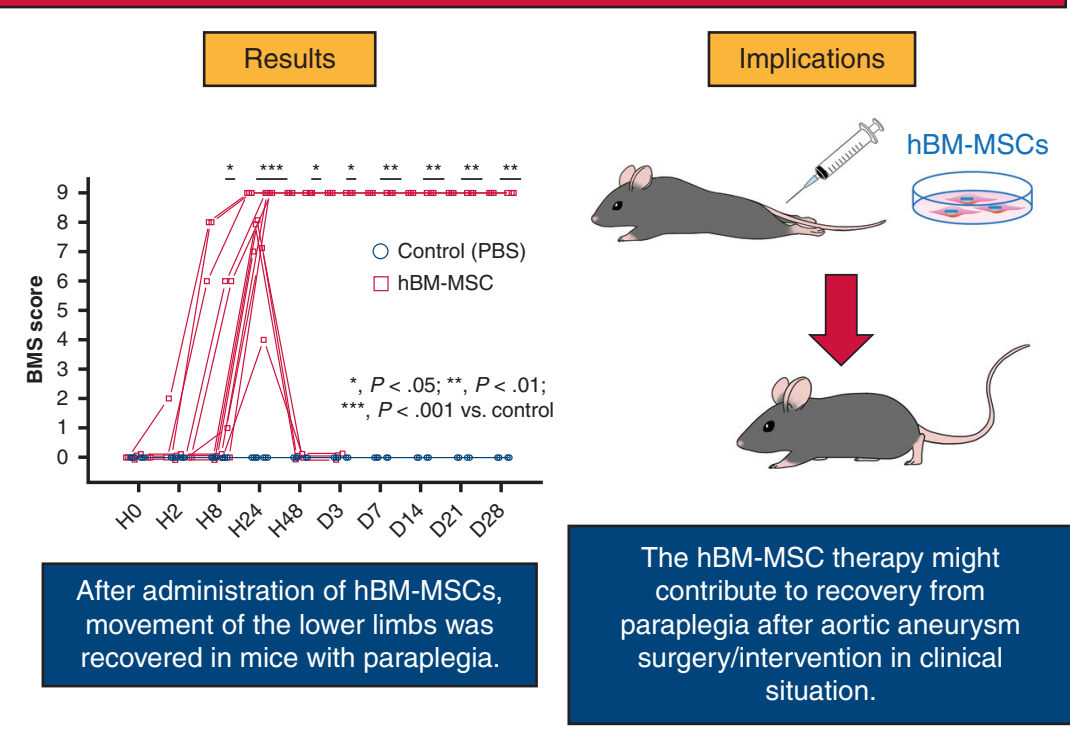

Two hours after inducing paraplegia by SCIR in mice,

hBM-MSCs were intravenously administered.

hBM-MSCs : human Bone Marrow Mesenchymal Stromal Cells BMS : Basso Mouse Scale

SCIR: Spinal Cord Ischemia/Reperfusion

FIGURE 8. We sought to investigate the efficacy of hBM-MSCs in a murine SCIR model. C57BL/6J mice were subjected to SCIR by crossclamping the aortic arch and left subclavian artery for 5.5 minutes. Two hours after reperfusion, hBM-MSCs (hBM-MSC group) or phosphate-buffered saline (control group) were intravenously injected without immunosuppressant. Hindlimb motor function was assessed until day 28 after reperfusion using the BMS. BMS score was 0 throughout the study period in all control mice. BMS score was significantly greater in the hBM-MSC group than the control group from hour 8 $(P<.05)$ to day $28(P<.01)$. The numbers of motor neurons at hour $24(P<.01)$ and day $28(P<.05)$ were significantly preserved in the hBM-MSC group than the control group. The hBM-MSC therapy might contribute to recovery from paraplegia after aortic aneurysm surgery/intervention in clinical situation. $h B M-M S C$, Human bone marrow mesenchymal stem/stromal cell; SCIR, spinal cord ischemia/reperfusion BMS, Basso Mouse Scale.

In the present study, all mice in the hBM-MSC group showed dramatic improvement in hindlimb motor function without any death until hour 24 after reperfusion compared with the control group. However, one-third of mice in the hBM-MSC group lapsed into paraplegia again and half of mice died until day 7 after reperfusion. In contrast, surviving mice in the hBM-MSC group maintained normal motor function without recurrence from hour 24 to day 28 . These findings suggest that intravenous injection of hBM-MSCs may attenuate or improve paraplegia, but not overall survival, after SCIR. We were able to get these findings because the present study was designed for long-term observation up to day 28 after reperfusion. hBM-MSCs were administrated to mice without any preconditioning procedure, however, recent studies have demonstrated that hypoxia-preconditioned MSCs augmented their paracrine abilities. ${ }^{33,34}$ The administration of hypoxia-preconditioned MSCs may be expected to have a further effect on reperfusion-injured spinal cord. Also, in this study, hypoxia in the spinal cord tissue after SCIR may have enhanced the paracrine function of transplanted hBM-MSCs.
Finally, we investigated the expression patterns of mRNA in the lumbar spinal cords at hour 24 after reperfusion, when the most significant difference in BMS score was observed between the 2 groups. mRNA expression levels of proinflammatory cytokines including tumor necrosis factor- $\alpha$, inducible nitric oxide synthase, and interleukin- $1 \beta$ were significantly lower and, whereas that of an antiapoptotic factor, IGF-1, and those of proangiogenic factors including vascular endothelial growth factor and hepatocyte growth factor in the lumber spinal cords were significantly elevated in the hBM-MSC group compared with the control group at hour 24. According to the previous studies, the release of proinflammatory cytokines associated with microglia activation ${ }^{12}$ and apoptosis of neurons ${ }^{10}$ in the spinal cord tissue have been proposed as mechanisms responsible for SCIR. Therefore, inhibition of mRNA of proinflammatory cytokines in the spinal cord by administration of hBM-MSCs may contribute to neuronal protection probably via regulation of microglia in the spinal cord. In animal cerebral ischemia models, MSCs are known to enhance neuroprotection against cerebral ischemia by upregulating IL-10 expression in peri-ischemic lesion through macrophages, 
dendritic cells, and peripheral blood mononuclear cells. ${ }^{35,36}$ However, in the present study, mRNA expression level of IL-10 in spinal cord at hour 24 after reperfusion was not elevated in hBM-MSC group compared with the control group. As reported by Smith and colleagues, ${ }^{12}$ the level of expression of cytokines in spinal cord tissue after SCIR changes dramatically by the hour. Therefore, in discussing the expression patterns of inflammatory cytokines and anti-inflammatory cytokines, it is important to evaluate the changes over time after reperfusion. The mRNA expression of IGF-1 was significantly greater in hBM-MSC group than control group, whereas there was no significant difference in the mRNA levels of B-cell lymphoma-xL and myeloid cell leukemia-1 between 2 groups. The motor neuron number had already been significantly lower in the control group compared with hBM-MSC group 24 hours after reperfusion (Figure 6, $C$ ). This result indicates that nerve cell death might have been completed until 24 hours after reperfusion. It might be appropriate to analyze the gene expression using the spinal cord tissue at the time point earlier than hour 24. Upregulation of mRNA expression of angiogenic factors may contribute to preservation of motor neurons through regeneration and/or repair of neurovascular unit. ${ }^{15}$ However, it remains unclear how the transplanted hBM-MSCs affected the gene expression of the injured spinal cord tissue in this study. Further mechanistic investigations will be required.

The present study has several limitations. First, this study focused on the therapeutic effect of hBM-MNCs for SCIR using immune-competent wild type mice by long-term observation. So, this study was not designed to evaluate serial changes of the spinal tissue environment including morphology and expressions of mRNAs and proteins during early stage after SCIR. Therefore, we did not sufficiently examine mechanisms of cell death in motor neurons or inflammatory changes in the spinal cord tissues. However, analysis of mRNA in the lumbar spinal cords at hour 24 after reperfusion at least demonstrated that intravenous injection of hBM-MSCs might inhibit proinflammatory cytokines and upregulate angiogenic factors in the reperfusion-injured spinal cord, although these results do not sufficiently support the involvement of antiapoptosis mechanisms in the preservation of motor neurons. Second, the sample size is small. The number of experimental mice was calculated with a mortality rate of $25 \%$ based on the preliminary experimental results (Figure 3). However, $50 \%$ of mice died at day 28 after reperfusion in both hBM-MSC and control groups. As a result, the BMS scores were analyzed only in 6 mice in hBM-MSC group and 3 in control group (Figure 5, A). In conducting experiments using this model in the future, we will prospectively calculate the number of examples with a mortality rate of $50 \%$. Finally, the current study examined the effects of $\mathrm{hBN}$ -
MSCs in female mice. In the future, it is necessary to carry out comparative studies between male and female mice.

In conclusion, physiological, histologic, and molecular examinations reveal that hBM-MSC therapy may potentially attenuate SCIR injury by preserving motor neurons (Figure 8), at least in part, through inhibition of proinflammatory cytokines and upregulation of antiapoptotic and proangiogenic factors in the reperfusion-injured spinal cord. These results encourage further investigations toward future clinical application.

\section{Conflict of Interest Statement}

The authors reported no conflicts of interest.

The Journal policy requires editors and reviewers to disclose conflicts of interest and to decline handling or reviewing manuscripts for which they may have a conflict of interest. The editors and reviewers of this article have no conflicts of interest.

\section{References}

1. Okita Y. Fighting spinal cord complication during surgery for thoracoabdominal aortic disease. Gen Thorac Cardiovasc Surg. 2011;59:79-90.

2. Alsawas M, Zaiem F, Larrea-Mantilla L, Almasri J, Erwin PJ, Upchurch GR Jr, et al. Effectiveness of surgical interventions for thoracic aortic aneurysms: a systematic review and meta-analysis. J Vasc Surg. 2017;66:1258-68.e8.

3. Acher C, Wynn M. Paraplegia after thoracoabdominal aortic surgery: not just assisted circulation, hypothermic arrest, clamp and sew, or TEVAR. Ann Cardiothorac Surg. 2012;1:365-72.

4. Qayumi AK, Janusz MT, Lyster DM, Gillespie KD. Animal model for investigation of spinal cord injury caused by aortic cross-clamping. J Invest Surg. 1997;10: 47-52.

5. Svensson LG, Von Ritter CM, Groeneveld HT, Rickards ES, Hunter SJ, Robinson MF, et al. Cross-clamping of the thoracic aorta. Influence of aortic shunts, laminectomy, papaverine, calcium channel blocker, allopurinol, and superoxide dismutase on spinal cord blood flow and paraplegia in baboons. Ann Surg. 1986;204:38-47.

6. Naslund TC, Hollier LH, Money SR, Facundus EC, Skenderis BS II. Protecting the ischemic spinal cord during aortic clamping. The influence of anesthetics and hypothermia. Ann Surg. 1992;215:409-15; discussion 415-6.

7. Taira Y, Marsala M. Effect of proximal arterial perfusion pressure on function, spinal cord blood flow, and histopathologic changes after increasing intervals of aortic occlusion in the rat. Stroke. 1996;27:1850-8.

8. Lang-Lazdunski L, Matsushita K, Hirt L, Waeber C, Vonsattel JP, Moskowitz MA, et al. Spinal cord ischemia. Development of a model in the mouse. Stroke. 2000;31:208-13.

9. Stone DH, Conrad MF, Albadawi H, Entabi F, Stoner MC, Cambria RP, et al. Effect of PJ34 on spinal cord tissue viability and gene expression in a murine model of thoracic aortic reperfusion injury. Vasc Endovasc Surg. 2009;43:444-51.

10. Kakinohana M, Kida K, Minamishima S, Atochin DN, Huang PL, Kaneki M, et al. Delayed paraplegia after spinal cord ischemic injury requires caspase-3 activation in mice. Stroke. 2011;42:2302-7.

11. Smith PD, Puskas F, Meng X, Cho D, Cleveland JC Jr, Weyant MJ, et al. Ischemic dose-response in the spinal cord: both immediate and delayed paraplegia. J Surg Res. 2012;174:238-44.

12. Smith PD, Puskas F, Meng X, Lee JH, Cleveland JC Jr, Weyant MJ, et al. The evolution of chemokine release supports a bimodal mechanism of spinal cord ischemia and reperfusion injury. Circulation. 2012;126:S110-7.

13. Yamanaka K, Sasaki N, Fujita Y, Kawamoto A, Hirata K-I, Okita Y. Impact of acquired and innate immunity on spinal cord ischemia and reperfusion injury Gen Thorac Cardiovasc Surg. 2016;64:251-9.

14. Friedenstein AJ, Chailakhjan RK, Lalykina KS. The development of fibroblast colonies in monolayer cultures of Guinea-pig bone marrow and spleen cells. Cell Tissue Kinet. 1970;3:393-403. 
15. Krueger TEG, Thorek DLJ, Denmeade SR, Isaacs JT, Brennen WN. Concise review: mesenchymal stem cell-based drug delivery: the good, the bad, the ugly, and the Promise. Stem Cells Transl Med. 2018;7:651-63.

16. Hoornaert CJ, Le Blon D, Quarta A, Daans J, Goossens H, Berneman Z, et al. Concise review: innate and adaptive immune recognition of allogeneic and xenogeneic cell transplants in the central nervous system. Stem Cells Transl Med. 2017;6:1434-41.

17. Katsuda T, Ochiya T. Molecular signatures of mesenchymal stem cell-derived extracellular vesicle-mediated tissue repair. Stem Cell Res Ther. 2015;6:212.

18. Luk F, de Witte SF, Korevaar SS, Roemeling-van Rhijn M, Franquesa M, Strini T, et al. Inactivated mesenchymal stem cells maintain immunomodulatory capacity. Stem Cells Dev. 2016;25:1342-54.

19. Galipeau J, Sensebe L. Mesenchymal stromal cells: clinical challenges and therapeutic opportunities. Cell Stem Cell. 2018;22:824-33.

20. Takahashi S, Nakagawa K, Tomiyasu M, Nakashima A, Katayama K, Imura T, et al. Mesenchymal stem cell-based therapy improves lower limb movement after spinal cord ischemia in rats. Ann Thorac Surg. 2018;105:1523-30.

21. Yin F, Guo L, Meng CY, Liu YJ, Lu RF, Li P, et al. Transplantation of mesenchymal stem cells exerts anti-apoptotic effects in adult rats after spinal cord ischemia-reperfusion injury. Brain Res. 2014;1561:1-10.

22. Basso DM, Fisher LC, Anderson AJ, Jakeman LB, McTigue DM, Popovich PG. Basso Mouse Scale for locomotion detects differences in recovery after spinal cord injury in five common mouse strains. J Neurotrauma. 2006;23:635-59.

23. Guo J, Qiu W, Soh SL, Wei S, Radda GK, Ong WY, et al. Motor neuron degeneration in a mouse model of seipinopathy. Cell Death Dis. 2013;4:e535.

24. Andrzejewska A, Lukomska B, Janowski M. Concise review: mesenchymal stem cells: from roots to boost. Stem Cells. 2019;37:855-64.

25. Shi E, Kazui T, Jiang X, Washiyama N, Yamashita K, Terada H, et al. Intrathecal injection of bone marrow stromal cells attenuates neurologic injury after spinal cord ischemia. Ann Thorac Surg. 2006;81:2227-33; discussion 2233-4.

26. Shi E, Kazui T, Jiang X, Washiyama N, Yamashita K, Terada H, et al. Therapeutic benefit of intrathecal injection of marrow stromal cells on ischemia-injured spinal cord. Ann Thorac Surg. 2007;83:1484-90.

27. Fang B, Wang H, Sun XJ, Li XQ, Ai CY, Tan WF, et al. Intrathecal transplantation of bone marrow stromal cells attenuates blood-spinal cord barrier disruption induced by spinal cord ischemia-reperfusion injury in rabbits. J Vasc Surg. 2013;58:1043-52.
28. Yoo DY, Kim DW, Chung JY, Jung HY, Kim JW, Yoon YS, et al. Cu, Zn-super oxide dismutase increases the therapeutic potential of adipose-derived mesenchymal stem cells by maintaining antioxidant enzyme levels. Neurochem Res 2016;41:3300-7.

29. Kurose T, Takahashi S, Otsuka T, Nakagawa K, Imura T, Sueda T, et al. Simulated microgravity-cultured mesenchymal stem cells improve recovery following spinal cord ischemia in rats. Stem Cell Res. 2019;41:101601.

30. De Miguel MP, Fuentes-Julian S, Blazquez-Martinez A, Pascual CY, Aller MA, Arias J, et al. Immunosuppressive properties of mesenchymal stem cells: ad vances and applications. Curr Mol Med. 2012;12:574-91.

31. Ohtaki H, Ylostalo JH, Foraker JE, Robinson AP, Reger RL, Shioda S, et al Stem/progenitor cells from bone marrow decrease neuronal death in global ischemia by modulation of inflammatory/immune responses. Proc Natl Acad Sci U S A. 2008; 105:14638-43.

32. Tsumuraya T, Ohtaki H, Song D, Sato A, Watanabe J, Hiraizumi Y, et al. Human mesenchymal stem/stromal cells suppress spinal inflammation in mice with contribution of pituitary adenylate cyclase-activating polypeptide (PACAP). $J$ Neuroinflammation. 2015;12:1-13.

33. Hu X, Yu SP, Fraser JL, Lu Z, Ogle ME, Wang JA, et al. Transplantation of hypoxia-preconditioned mesenchymal stem cells improves infarcted heart function via enhanced survival of implanted cells and angiogenesis. J Thorac Cardiovasc Surg. 2008;135:799-808.

34. Lee JH, Yoon YM, Lee SH. Hypoxic preconditioning promotes the bioactivities of mesenchymal stem cells via the HIF-1alpha-GRP78-Akt axis. Int J Mol Sci. 2017;18:1320.

35. Liu N, Chen R, Du H, Wang J, Zhang Y, Wen J. Expression of IL-10 and TNFalpha in rats with cerebral infarction after transplantation with mesenchymal stem cells. Cell Mol Immunol. 2009;6:207-13.

36. Li J, Zhu H, Liu Y, Li Q, Lu S, Feng M, et al. Human mesenchymal stem cell transplantation protects against cerebral ischemic injury and upregulates interleukin-10 expression in Macacafascicularis. Brain Res. 2010;1334:65-72.

Key Words: paraplegia, spinal cord ischemia, spinal cord reperfusion injury, human bone marrow mesenchymal stromal cells, thoracic aortic surgery 


\section{E-References}

E1. Kroner A, Greenhalgh AD, Zarruk JG, Passos Dos Santos R, Gaestel M, David S. TNF and increased intracellular iron alter macrophage polarization to a detrimental M1 phenotype in the injured spinal cord. Neuron. 2014;83: 1098-116.

E2. Tsumuraya T, Ohtaki H, Song D, et al. Human mesenchymal stem/stromal cells suppress spinal inflammation in mice with contribution of pituitary adenylate cyclase-activating polypeptide (PACAP). J Neuroinflammation. 2015;12: $1-13$.

E3. Kamei N, Kwon SM, Alev C, Ishikawa M, Yokoyama A, Nakanishi K, et al. Lnk deletion reinforces the function of bone marrow progenitors in promoting neo- vascularization and astrogliosis following spinal cord injury. Stem Cells. 2010; 28:365-75.

E4. He Y, Peng X, Wu T, Yang W, Liu W, Zhang J, et al. Restricting the induction of NGF in ovarian stroma engenders selective follicular activation through the mTOR signaling pathway. Cell Death Dis. 2017;8:e2817.

E5. Iwasawa M, Miyazaki T, Nagase Y, Akiyama T, Kadono Y, Nakamura M, et al. The antiapoptotic protein Bcl-xL negatively regulates the bone-resorbing activity of osteoclasts in mice. J Clin Invest. 2009;119:3149-59.

E6. Fontaine MAC, Westra MM, Bot I, Jin H, Franssen AJPM, Bot M, et al. Low human and murine Mcl-1 expression leads to a pro-apoptotic plaque phenotype enriched in giant-cells. Sci Rep. 2019;9:14547. 


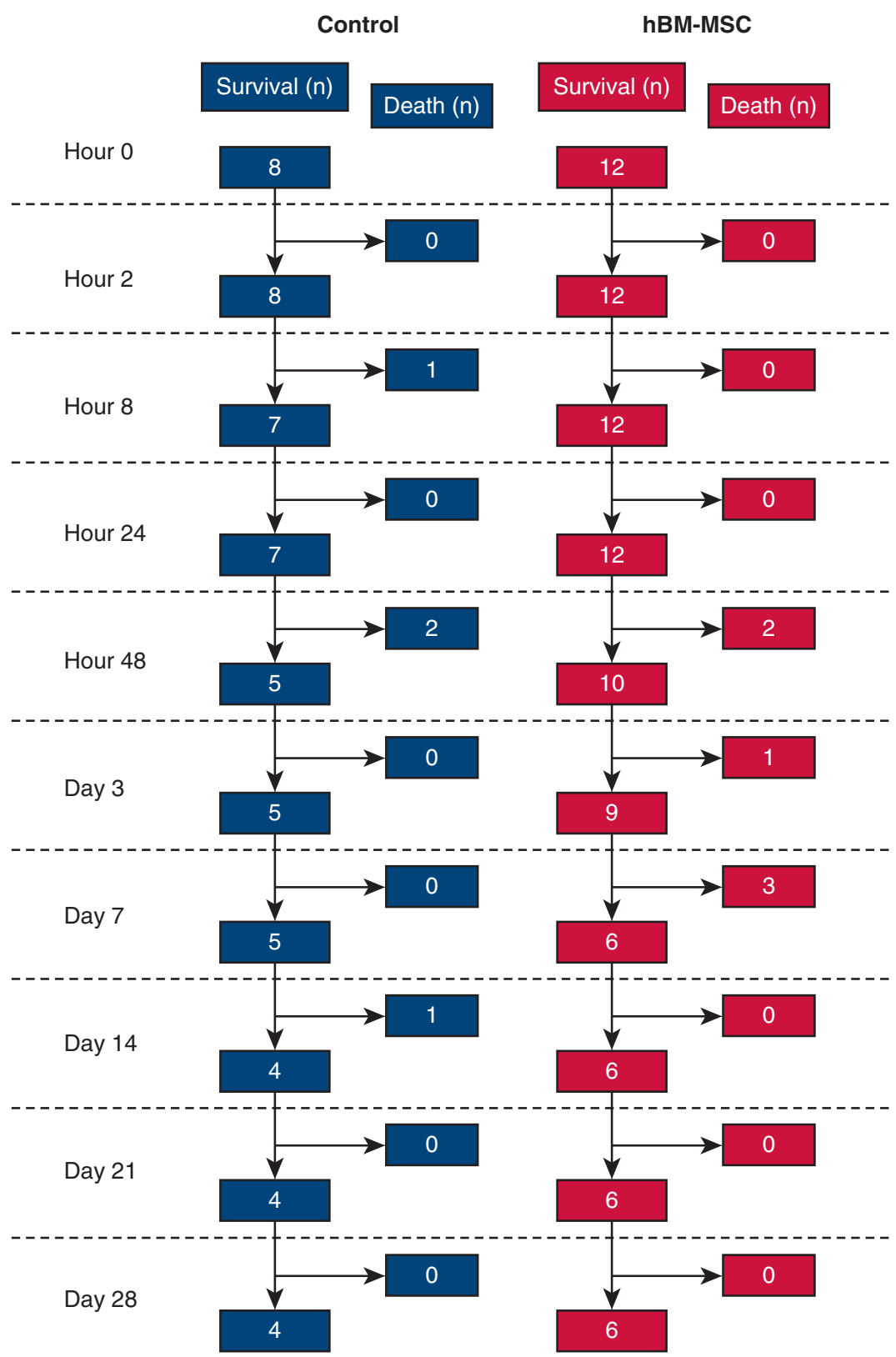

FIGURE E1. The number of survived and dead mice at each time point after reperfusion. $h B M-M S C$, Human bone marrow mesenchymal stem/stromal cell. 


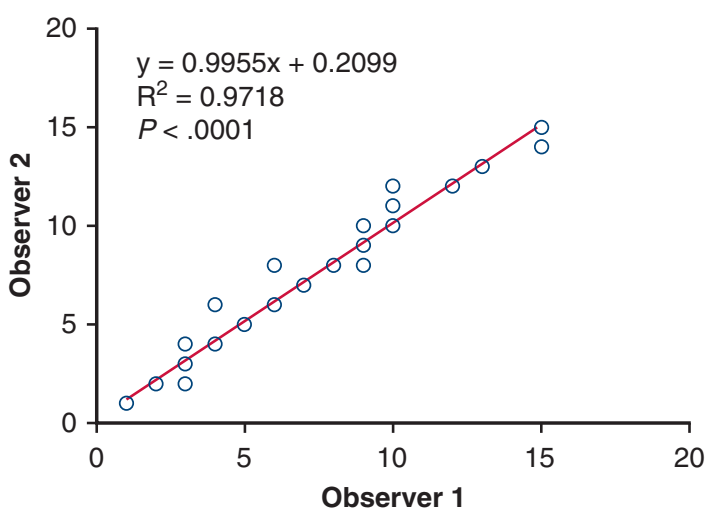

A

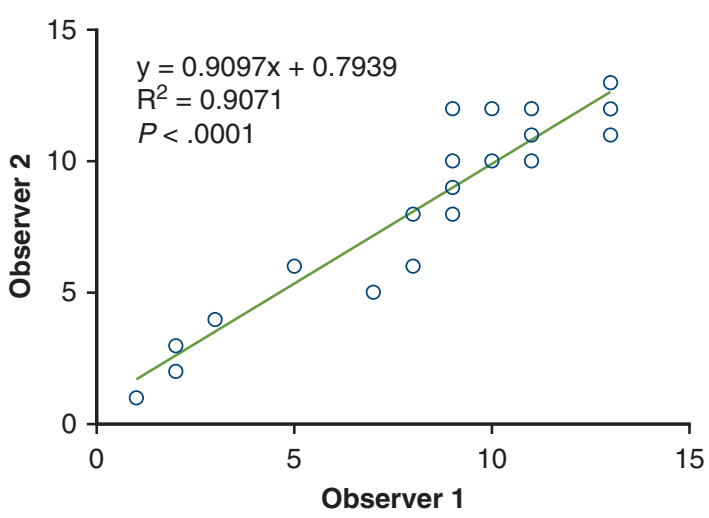

B

FIGURE E2. Interobserver variation of Neu-N-positive motor neurons in the ventral horn at hour 24 (A) and at day 28 (B) by linear regression analysis.

TABLE E1. Specific primers for real-time RT-PCR (all sequences are mouse specific)

\begin{tabular}{|c|c|c|c|}
\hline \multirow[b]{2}{*}{ Gene } & \multicolumn{2}{|c|}{ Sequence $5^{\prime}$ to $3^{\prime}$} & \multirow[b]{2}{*}{ Ref. } \\
\hline & Forward sequence & Reverse sequence & \\
\hline Tnfa & TTGCTCTGTGAAGGGAATGG & GGCTCTGAGGAGTAGACAATAAAG & E1 \\
\hline$i N O s$ & GAACGGAGAACGTTGGATTTG & TCAGGTCACTTTGGTAGGATTT & E1 \\
\hline$I l l b$ & TCCAGGATGAGGACATGAGCAC & GAACGTCACACACCAGCAGGTTA & E2 \\
\hline Igfl & GCTAAACACTTGGCAGGAGG & ATGAAGCAAAATGTGCGTTG & E3 \\
\hline$N g f$ & TGTGCCTCAAGCCAGTGAAAT & ACCTTTATTGGGCCCAGACAC & E4 \\
\hline$B d n f$ & CAGTGGCTGGCTCTCTTACC & TGCTGCCATGCATAAAACAT & E3 \\
\hline Vegf & TCTCCCAGATCGGTGACAGT & GGGCAGAGCTGAGTGTTAGC & - \\
\hline Angl & AАCCTCACCCTGCAAAGATG & CACAGATGGCCTTGATGTTG & - \\
\hline$H g f$ & TGAGTGGGCCACCATAATCT & GGGCTGAAAAGATTGGATCA & - \\
\hline Bcl2l1 & GCTGGGACACTTTTGTGGAT & TGTCTGGTCACTTCCGACTG & E5 \\
\hline Mcll & AAGAGGCTGGGATGGGTTTGT & AGTCCCCTATTGCACTCACAAG & E6 \\
\hline Gapdh & AGGGCTGCTTTTAACTCTGGT & СCCCACTTGATTTTGGAGGGA & - \\
\hline
\end{tabular}


TABLE E2. Comparison of the effect of spinal ischemic time on motor function

\begin{tabular}{|c|c|c|c|c|}
\hline \multirow[b]{2}{*}{ SCI time, min } & \multicolumn{4}{|c|}{ BMS at each time point after reperfusion } \\
\hline & Hour 0 & Hour 8 & Hour 24 & Hour 48 \\
\hline 4 & 0 & 9 & 9 & 9 \\
\hline 4 & 0 & 9 & 9 & 9 \\
\hline 4 & 0 & 9 & 9 & 9 \\
\hline 4.5 & 3 & 9 & 9 & 0 \\
\hline 4.5 & 0 & 9 & 9 & 9 \\
\hline 4.5 & 0 & 9 & 0 & 0 \\
\hline 4.5 & 0 & 9 & 9 & 9 \\
\hline 5 & 0 & 1 & 0 & 0 \\
\hline 5 & 0 & 0 & Death & \\
\hline 5 & 0 & 0 & 0 & 0 \\
\hline 5 & 0 & 0 & Death & \\
\hline 5 & 0 & 0 & 9 & 9 \\
\hline 5 & 0 & 0 & 9 & 9 \\
\hline 5 & 0 & 0 & 9 & 9 \\
\hline 5.5 & 0 & 0 & 0 & 0 \\
\hline 5.5 & 0 & 0 & Death & \\
\hline 5.5 & 0 & 0 & 0 & 0 \\
\hline 5.5 & 0 & 0 & 0 & 0 \\
\hline 6 & 0 & 0 & Death & \\
\hline 6 & 0 & 0 & 0 & 0 \\
\hline 6 & 0 & 0 & Death & \\
\hline 6 & 0 & 0 & Death & \\
\hline
\end{tabular}

SCI, Spinal cord ischemia; $B M S$, Basso Mouse Scale.

TABLE E3. Perioperative physiological variables in mice observed until day 28 after reperfusion

\begin{tabular}{lccc}
\hline & Control $(\mathbf{N}=\mathbf{8})$ & hBM-MSC $(\mathbf{N}=\mathbf{1 2})$ & $\boldsymbol{P}$ value \\
\hline Age, wk & $15.5 \pm 2.8$ & $16.5 \pm 1.9$ & .5360 \\
Body weight, $\mathrm{g}$ & $21.9 \pm 2.0$ & $22.1 \pm 1.2$ & .7567 \\
SCI time, min & 5.5 & 5.5 & - \\
Mean flow reduction $(\%)$ during ischemia & $92.8 \pm 1.9$ & $91.8 \pm 1.6$ & .0889 \\
Mean rectal temperature $\left({ }^{\circ} \mathrm{C}\right)$ during ischemia & $36.7 \pm 0.6$ & $36.4 \pm 0.5$ & .0950 \\
\hline
\end{tabular}

hBM-MSC, Human bone marrow mesenchymal stem/stromal cell; $S C I$, spinal cord ischemia. 
TABLE E4. Perioperative physiological variables in mice killed humanely at hour 24 after reperfusion for histologic and mRNA expression analysis

\begin{tabular}{lccc}
\hline & Control $(\mathbf{N}=\mathbf{5})$ & hBM-MSC $(\mathbf{N}=\mathbf{6})$ & $\boldsymbol{P}$ value \\
\hline Age, wk & $13.5 \pm 2.6$ & $15.3 \pm 4.3$ & .5161 \\
Body weight, $g$ & $21.4 \pm 1.1$ & $21.8 \pm 1.6$ & .9273 \\
SCI time, min & 5.5 & 5.5 & - \\
Mean flow reduction $(\%)$ during ischemia & $92.8 \pm 1.7$ & $91.9 \pm 1.6$ & 3153 \\
Mean rectal temperature $\left({ }^{\circ}\right)$ during ischemia & $36.6 \pm 0.8$ & $36.7 \pm 0.2$ & .1982 \\
\hline
\end{tabular}

